\title{
Endocytosis and Signaling during Development
}

\author{
Christian Bökel and Michael Brand \\ Center for Regenerative Therapies Dresden and Biotechnology Center, Technische Universität Dresden, \\ 01307 Dresden, Germany \\ Correspondence: michael.brand@biotec.tu-dresden.de
}

The development of multicellular organisms relies on an intricate choreography of intercellular communication events that pattern the embryo and coordinate the formation of tissues and organs. It is therefore not surprising that developmental biology, especially using genetic model organisms, has contributed significantly to the discovery and functional dissection of the associated signal-transduction cascades. At the same time, biophysical, biochemical, and cell biological approaches have provided us with insights into the underlying cell biological machinery. Here we focus on how endocytic trafficking of signaling components (e.g., ligands or receptors) controls the generation, propagation, modulation, reception, and interpretation of developmental signals. A comprehensive enumeration of the links between endocytosis and signal transduction would exceed the limits of this review. We will instead use examples from different developmental pathways to conceptually illustrate the various functions provided by endocytic processes during key steps of intercellular signaling.

$T_{a}^{\text {has }}$ he evolution of multicellular life introduced a division of labor between specialized cells, which strongly increased demand for intercellular communication both during development and homeostasis of the adult organism (Kaiser 2001). At the genomic level this is reflected by a dramatic expansion of the surface receptor signalome in all metazoan lineages (Ben-Shlomo et al. 2003). However, the idea that intercellular communication drives the organization and patterning of the embryo precedes the identification of the responsible molecules. Induction (i.e., the ability of one group of cells within a developing organism to influence the cell-fate choices), morphogenesis, and differentiation of other cell populations, was firmly established by the experiments of Spemann and Mangold
(1924) and has become one of the most important concepts of developmental biology. The related concept of the morphogen, whereby a cell can identify its position within a tissue by using the local levels of a secreted molecule forming a concentration gradient as a proxy for its distance from the source, was famously illustrated by the "French flag Model" by Wolpert (1969).

Since then, examples of developmental patterning events following these two paradigms have been identified in all developmental model systems, ranging from worms and flies to amphibians, fish, and mice, and even humans. Surprisingly, despite the huge variety in the eventual outcome of metazoan embryonic development, it turned out that most individual

Editors: Sandra L. Schmid, Alexander Sorkin, and Marino Zerial

Additional Perspectives on Endocytosis available at www.cshperspectives.org

Copyright (C) 2014 Cold Spring Harbor Laboratory Press; all rights reserved; doi: 10.1101/cshperspect.a017020

Cite this article as Cold Spring Harb Perspect Biol 2014;6:a017020 
patterning events are performed by a restricted set of signal-transduction pathways that are used repeatedly and in varying cellular contexts (Pires-daSilva and Sommer 2003; Perrimon et al. 2012).

Because animal embryos differ in shape and size, closely related pathways must function over similarly varying spatial and temporal scales, potentially even at successive developmental stages within the same embryo. To understand how the limited, intercellular signaling repertoire is modulated to accommodate the varying patterning needs arising within the different developmental contexts, it is necessary to study the signal-transduction machinery at the molecular level. In recent years, major progress has been made in understanding the mechanistic links between the protein trafficking machinery and the generation and interpretation of morphogenetic signals.

Traditionally, endocytosis was seen as a means of removing activated receptors and their bound ligands from the surface of the signalreceiving cells, thereby terminating the signals. However, positive effects of endocytosis on signal transduction have recently been identified for many different pathways including, among others, receptor tyrosine kinases (RTKs), TGF$\beta$, TNF- $\alpha$, Toll-like receptor, Wnt, and Notch signal-transduction cascades (Miaczynska et al. 2004; Platta and Stenmark 2011). In many of these examples, endosomes act as platforms where the activated receptors can interact with specific downstream components of the signaltransduction machinery (Sadowski et al. 2009; Miaczynska and Bar-Sagi 2010). Trafficking of the receptors into and out of such endosomes may thus provide another tier for the regulation of the signaling output that allows temporal and spatial modulation of the signals independent of ligand presentation. In addition, the endocytic pathway has recently also become implicated in signaling events that precede the intracellular transduction of the signal. In this review, we therefore focus on how the endocytic machinery participates in the generation, propagation, reception, and interpretation of intercellular signals in the context of animal development.

\section{INVOLVEMENT OF THE ENDOCYTIC PATHWAY IN SIGNAL GENERATION}

Intercellular signaling in development typically begins with the release of an extracellular signal from one group of cells that will then spread through the target tissue and alter the behavior of the signal-receiving cells. It may therefore appear surprising that trafficking through endocytic compartments of the ligand-producing cells is already implicated at this first step of signal transduction.

In Drosophila, the Wnt family growth factor Wingless $(\mathrm{Wg})$ is involved in many aspects of embryonic and larval development, typically acting over several cell diameters (Zecca et al. 1996; Neumann and Cohen 1997). Wg is secreted as a hydrophobic, doubly lipidated molecule, and this posttranslational modification is required both for $\mathrm{Wg}$ secretion and signaling activity (Port and Basler 2010). Following exit from the endoplasmic reticulum (ER), Wnts are targeted for secretion by an interaction with Wntless (Wls, also called Evi or Sprinter) that acts as a Wnt cargo receptor within the Golgi. This interaction is highly specific and essential for Wnt secretion not only in flies (Banziger et al. 2006; Bartscherer et al. 2006; Goodman et al. 2006) but also planarians (Adell et al. 2009), nematodes (Coudreuse et al. 2006; Prasad and Clark 2006), and vertebrates (Fu et al. 2009; Kim et al. 2009). Following dissociation of the Wls / Wnt complex in the trans-Golgi network, Wls is internalized from the plasma membrane by clathrin-mediated endocytosis (Pan et al. 2008; Gasnereau et al. 2011) and recycled toward the Golgi with the help of the retromer complex (Coudreuse et al. 2006; Prasad and Clark 2006; Belenkaya et al. 2008; Franch-Marro et al. 2008; Pan et al. 2008; Port et al. 2008; Yang et al. 2008; Kim et al. 2009) and the sorting nexin SNX3 (Harterink et al. 2011; Zhang et al. 2011). Thus, endocytosis contributes to Wnt signaling by the retrieval and recycling of Wls, an essential and limiting factor for Wnt secretion (Fig. 1).

However, at least in certain signaling contexts, the Wnt ligands themselves are also trafficked through the endocytic pathway of the signal-producing cells. In the neuromuscular 


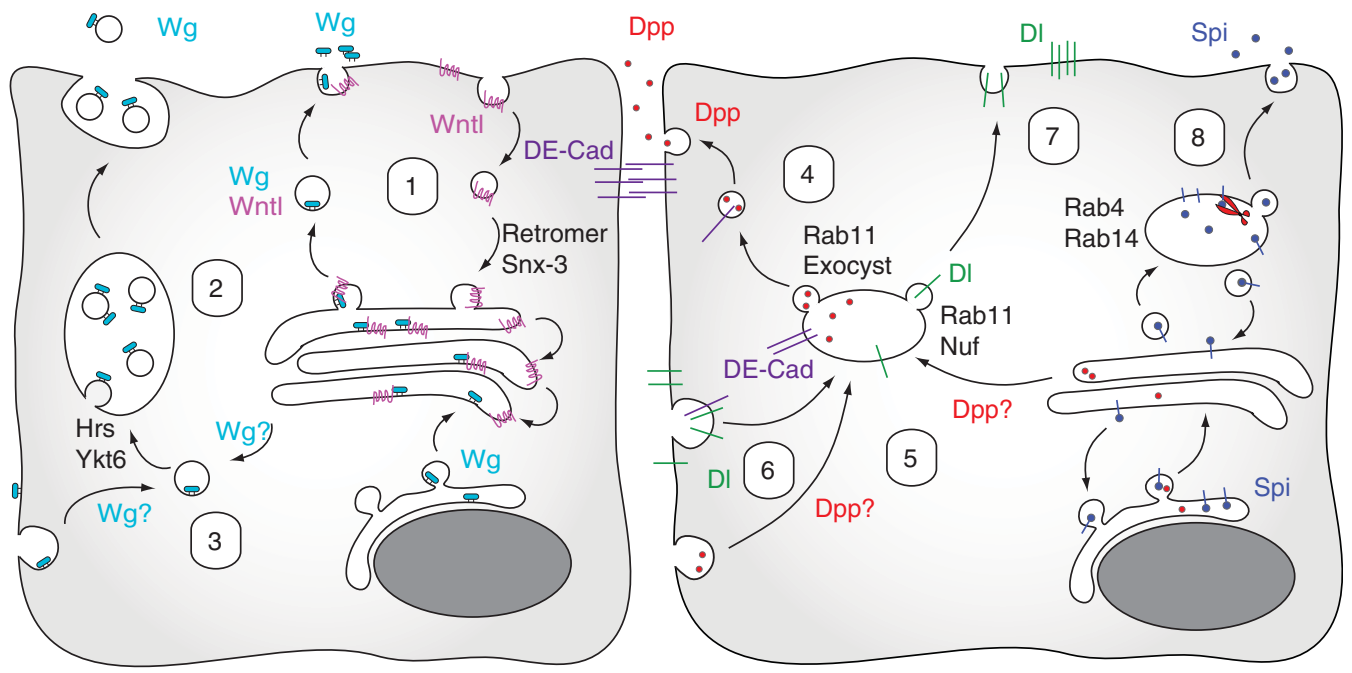

Figure 1. Endocytosis and signal generation. Secretion of the lipidated growth factor Wg (light blue) requires the cargo receptor Wntl ( pink). Retromer and Snx-3-mediated recycling of Wntl from the plasma membrane to the Golgi (1) is essential for maintaining Wg secretion. Wg can also be secreted via exosomes that are derived from multivesicular bodies (MVBs) whose formation is driven by Hrs and Ykt6 (2). Whether Wg reaches the MVBs directly or via the plasma membrane is unclear (3). In the stem cell niche of the fly testis the bone morphogenetic protein (BMP) family growth factor Dpp (red) is locally secreted at DE-cadherin (violet) containing adherens junctions by hitchhiking on vesicles mediating exocyst-driven recycling of internalized cadherin from Rab11positive endosomes to the junctions (4). How Dpp reaches these endosomes is again not known (5). In contrast, the Notch ligand Dl (green) is internalized at the basal side (6) before transcytosis via a Rab11 and Nuf-positive recyling compartment (7) for presentation at the apical surface. In fly neurons, the TGF- $\alpha$-like growth factor Spi (dark blue) is proteolytically released in Rab4 and Rab14 endosomes (8), which allows the soluble, mature form to escape retrograde transport of the precursor form back to the ER.

junction of the fly larva, Wg is secreted in association with exosomes together with Wtls (Korkut et al. 2009). Exosome-mediated secretion of a protein requires the passage of the cargo through the endocytic pathway, its sorting into intralumenal vesicles of multivesicular bodies (MVBs), and the fusion of these MVBs with the plasma membrane. Consistently, synaptic $\mathrm{Wg}$ secretion requires the endosomal regulator Rab11 and its effector Myosin5A (Koles et al. 2012). Exosome-associated secretion of active Wnt ligands has also been observed in fly and human cultured cells (Gross et al. 2012; Beckett et al. 2013) as well as the developing fly larva. There, secretion of active Wg involves the activity of the ESCRT-0 component Hrs and the RSnare Ykt6 that are involved in MVB biogenesis (Gross et al. 2012). Conceivably, this exosomemediated mode of Wnt secretion (Fig. 1) may also contribute to long-range $\mathrm{Wg}$ signaling in the Drosophila larval wing disc (Greco et al. 2001). However, Wnt family proteins clearly also use several other modes of secretion that do not appear to rely on prior endosomal trafficking of the ligand within the secreting cells (Port and Basler 2010).

However, exosome formation is not the most common pathway used for protein trafficking from endocytic compartments to the plasma membrane. Instead, proteins are typically targeted to one of several recycling pathways characterized by the presence of (e.g., Rab4 or Rab11), where they are sorted into vesicles destined for the plasma membrane. In Drosophila, this pathway has been co-opted for the directed delivery of BMP ligands in the context of spatially restricted stem cell niche signaling (Fig. 1). In the fly testis, signals mediated by the bone morphogenetic protein (BMP) ligands Dpp and Gbb emanate from a group of somatic 
cells termed hub. These BMP niche signals suppress germ-cell differentiation, thus maintaining the stemness of adjacent germline stem cells (Losick et al. 2011). Although BMPs typically act as long-range morphogens (Bollenbach et al. 2008; Perrimon et al. 2012), the niche signals in the testis act strictly between adjacent cells (Michel et al. 2011). Using fluorescently tagged Dpp ligands and fluorescence-based reporters for BMP receptor activation, it could be shown that BMP-mediated niche signaling is tightly confined to the adherens junctions between niche and stem cells, although BMP receptors are also present elsewhere on the target cell surface. This subcellular spatial restriction depends on localized release of the ligand at the junctions, which is achieved by hitchhiking of Dpp on vesicles that recycle internalized cadherins from a Rab11-positive endosomal compartment to the junctions (Michel et al. 2011). Cadherin recycling to preexisting adherens junctions both in flies (Langevin et al. 2005; Blankenship et al. 2007) and mammalian cells (Nejsum and Nelson 2007) requires the exocyst complex, a multiprotein complex required for local interaction between vesicles and membrane that directs protein release to specific sites at the plasma membrane (He and Guo 2009). Knockdown of the exocyst components Sec6 and Sec8 therefore traps BMP ligands in an enlarged Rab11-positive recycling compartment together with DE-cadherin (Michel et al. 2011). Intriguingly, inactivation of the exocyst in the ligand-producing cells also affects Dpp signaling in the larval wing disc (Michel et al. 2011), suggesting that ligand secretion via the Rab11positive recycling compartment may also act in the context of long-range BMP signaling (see below).

The endosomal machinery has also been implicated in the release of the TGF- $\alpha$-like growth factor Spitz (Spi) during Drosophila eye development. Spi is secreted as a transmembrane precursor that is retained in the ER by retrograde trafficking (Lee et al. 2001; Tsruya et al. 2002). Productive Spi release specifically from axons occurs via Rab4- and Rab14-positive endosomes (Yogev et al. 2010), where the inactive Spi precursor is cleaved by Rhomboid-
3, a member of the Rhomboid family of intramembrane proteases (Urban et al. 2001), allowing the mature growth factor to escape the route back to the ER (Fig. 1).

A final example for a role of endocytosis in ligand generation can be found in the Drosophila Notch pathway (Fig. 1), where in epithelial contexts the membrane-associated ligand Delta (Dl) must be internalized basally with the help of the E3 ubiquitin ligase Neuralized (Neu) before recycling and productive presentation on the apical side (Rajan et al. 2009; Benhra et al. 2010). Consistently, recycling seems to be dispensable for the presentation of $\mathrm{Dl}$ by germ cells or neurons (Windler and Bilder 2010; Banks et al. 2011). Cell-type-specific endocytosis and recycling of $\mathrm{Dl}$ also plays a role during the cell-fate specification that follows the asymmetric division of a sensory organ precursor cell in the fly pupa. Immediately after division, a prominent Rab11-positive recycling compartment is only reestablished in the pIIb daughter cell but remains absent from its sibling pIla owing to the asymmetric segregation of the Rab11 cofactor Nuclear fallout (Nuf) (Emery et al. 2005). In consequence, $\mathrm{Dl}$ is thought to be preferentially presented by the pIIb daughter cell and to activate Notch in the pIIa sibling cell.

\section{ENDOCYTOSIS AND THE PROPAGATION AND SHAPING OF EXTRACELLULAR SIGNALS}

One of the key concepts in developmental biology is the patterning of tissues by morphogens (Wolpert 1969). A rough estimate of the diffusion properties of typical growth factor proteins shows that diffusive processes can in principle account for the morphogen spreading over the temporal and spatial scales typically required during embryogenesis (Crick 1970; Müller and Schier 2011). However, mathematical arguments that are discussed in detail in the review by González-Gaitán and Jülicher (2014) and by (Wartlick et al. 2009) show that stable formation of gradients by a secretion-diffusion-clearance (SDC) mechanism requires the presence of a sink that reduces the concentration of the morphogen within the target tissue. One possible 
way in which an organism can establish such a sink is the endocytic internalization and sequestration or degradation of the ligands. This may conveniently be achieved by receptor-mediated endocytosis into the signal-receiving cells using the same receptors that also transduce the morphogen signals.

Examples for such a mechanism include the Dpp morphogen gradient in the Drosophila larval wing disc. Dpp emanates from a narrow strip of cells along the anteroposterior compartment boundary, from which it spreads through the target tissue forming an anteroposterior gradient (Lecuit et al. 1996; Nellen et al. 1996; Entchev et al. 2000; Teleman and Cohen 2000). The Dpp gradient is subsequently translated into corresponding BMP receptor activation (Michel et al. 2011) and transcription factor phosphorylation gradients (Tanimoto et al. 2000; Teleman and Cohen 2000; Bökel et al. 2006) that control patterning and growth of the developing wing disc. Dpp is specifically internalized into target cells by interaction with its receptor Thickveins (Tkv). Consistent with a SDC mechanism for gradient formation, fractional sorting of the endocytosed Dpp toward degradation then determines the slope of the gradient. Overexpression of a constitutively active form of the small GTPase Rab7, which promotes the transport of internalized cargo to degradative compartments, leads to a steeper Dpp gradient (Entchev et al. 2000).

Similar mechanisms also operate during fibroblast growth factor (FGF) signaling in vertebrate development (Bökel and Brand 2013). During zebrafish gastrulation stages, FGF-8 gradients emanating from sources at the blastoderm margin and the anterior hindbrain anlage contribute to dorsoventral patterning of the embryo (Fürthauer et al. 1997) and anteroposterior segmentation of the nervous system (Reifers et al. 1998). Long-range propagation of FGF ligands through the tissue occurs by free diffusion within the extracellular space (Yu et al. 2009). However, receptors and a subpopulation of the FGF ligands interact tightly with the heparan sulfate proteoglycans of the pericellular matrix before signaling (Bökel and Brand 2013). As for Dpp in the fly wing, the slope of the extracellular
FGF gradient is regulated by receptor-mediated internalization of the bound morphogen (Fig. 2A). Overexpression of Rab5 thus promotes FGF-8 endocytosis into cells close to the source, steepens the FGF-8 gradient, and reduces the width of the nested FGF target gene domains. Conversely, inactivation of Rab5 by morpholino injection or blocking dynamin-mediated endocytosis using a dominant-negative dynamin mutant led to the expansion of both the FGF gradient and its target genes (Scholpp and Brand 2004; Yu et al. 2009).

However, in situations in which the intensity or position of the ligand source is changing rapidly, SDC-based formation of stable steady-state gradients may not be possible. In such cases, specialized clearance receptors may come into play whose only role appears to lie in the reduction of extracellular ligand levels. One example for such a mechanism can be found in the homing of the primordial germ cells to the gonadal anlage during vertebrate development (Fig. 2B). These cells use the receptor CXCR4 to follow a gradient of the chemokine CXCL12/SDF-1 both in zebrafish (Doitsidou et al. 2002; Knaut et al. 2003) and mouse (Molyneaux et al. 2003). Correct migration of the germ cells also requires CXCR7, a high-affinity decoy receptor for the CXCL12/SDF-1 ligand. CXCR7 is broadly expressed but conspicuously absent from both the migrating germ cells and the CXCL12/ SDF-1 source at the gonadal anlage (Boldajipour et al. 2008). CXCR7 on its own does not appear to have a signaling role in PGC migration. Instead, its internalization and delivery of bound ligand to a LAMP-1-positive degradative compartment is required to reduce CXCL12/ SDF-1 levels, ensuring the rapid formation of local and dynamic ligand gradients that can be interpreted by isolated and highly motile target cells. In the absence of CXCR7 the spatial information required for correct germ-cell migration is lost, presumably because CXCL12/SDF-1 levels are ubiquitously high (Boldajipour et al. 2008). CXCR7 membrane levels and thus CXCL12/SDF-1 concentrations have to be finely tuned. CXCR7 surface levels are reduced by preventing $\beta$-arrestin-dependent sorting of the decoy receptor from the late endosomal/lyso- 
A Standard SDC mechanism

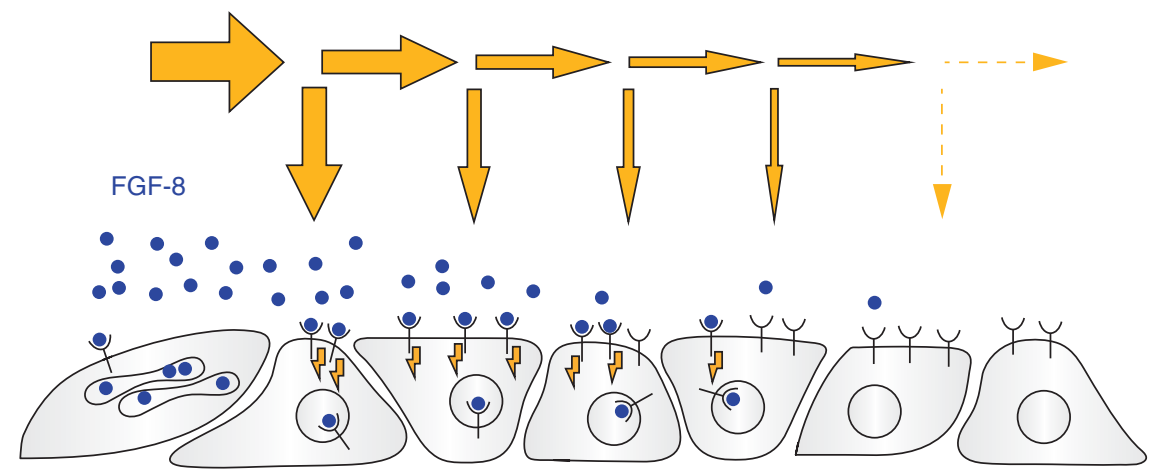

B Clearance receptor-mediated gradient CXCL12

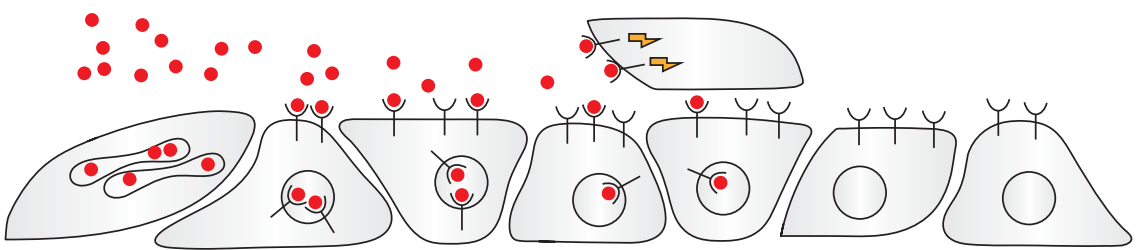

Figure 2. Shaping extracellular morphogen gradients by endocytosis. (A) The zebrafish FGF-8 gradient is a typical example of a gradient formed by a secretion-diffusion-clearance (SDC) mechanism. FGF-8 (blue) emanates form a localized source of cells. The shape of the decay curve is determined by the ratio of lateral diffusion (horizontal arrows) and internalization (vertical arrows) that is mediated by the signaling FGF receptors. $(B)$ During germ-cell migration, the pool of cells expressing the signaling receptor is too small and mobile to act as a sink for the ligand. Internalization of the CXCL12 chemokine (red) by the nonsignaling receptor CXCR7 in the surrounding tissue is required for the formation of an interpretable CXCL12 gradient.

somal degradation route to toward the recycling pathway. This alone increases CXCL12/SDF-1 levels sufficiently to interfere with germ-cell migration (Mahabaleshwar et al. 2012).

Although the above examples emphasize the importance of endocytosis for the "clearance" part of shaping the morphogen gradients via the SDC mechanism, ligand internalization may also contribute to the "diffusion" part. Returning to Dpp in the Drosophila third instar larval wing disc, it has been proposed that the formation of this long-range BMP morphogen gradient is mediated by planar transcytosis. According to this model, Dpp secreted by the source cells is internalized by the receiving cells, followed by fractional sorting between the recycling and degradation pathways, and nondirectional resecretion. At tissue level, this amounts to an effectively diffusive ligand propagation across the disc able to form a gradient by an SDC mechanism (Entchev et al. 2000). Evidence for this model comes from "shadows" in the level of intracellular Dpp that form behind cells unable to internalize Tkv and Dpp owing to a block in dynamin-mediated endocytosis (Entchev et al. 2000). Additional support comes from quantitative fluorescence recovery after photobleaching (FRAP) experiments on discs where endocytosis is blocked in all cells outside the Dpp-expressing cells (Kicheva et al. 2007). However, the planar transcytosis model of Dpp gradient formation has been disputed based on experiments in which levels of Tkv or the heparan sulfate proteoglycan Dally were clonally altered, and restricted extracellular diffusion models were proposed instead (Belenkaya et al. 2008; Schwank et al. 2011). For the moment the issue remains open, especially as another alter- 
native mechanism of Dpp spreading that is based on cytoplasmic extensions called cytonemes must be considered (Hsiung et al. 2005; Roy et al. 2011). Intriguingly, cytoneme- or planar-transcytosis-based mechanisms might explain why increased endocytosis owing to Rab5 overexpression increases the range of the Dpp gradient in the wing disc (Entchev et al. 2000). In contrast, for SDC-based mechanisms acting on an extracellularly diffusing ligand pool the same treatment would be expected to restrict ligand and target gene range, as observed for the zebrafish FGF-8 morphogen gradient (Scholpp and Brand 2004; Yu et al. 2009).

\section{ACTIVATION OF SIGNALING PATHWAYS BY ENDOCYTOSIS}

Once a ligand arrives at its target cell and binds to its receptor, events must be triggered at the molecular level that convey this information across the plasma membrane. Endocytosis can again act at this early step of signal transduction. Although it is difficult to delimit boundaries sharply, we would, for the purposes of this review, like to separate these early events from later, downstream steps of the signal-transduction cascade that rely on a preexisting activated state of the surface receptor and will be addressed below.

It has been known for some time that Notch signaling in Drosophila strictly requires endocytosis in the ligand-presenting cells (Seugnet et al. 1997; Parks et al. 2000). In Drosophila, the DSL (Delta/Serrate/Lag-2) family Notch ligands Delta (Dl) and Serrate (Ser) are monoubiquitinated by the ubiquitin ligases Neuralized (Neu) (Deblandre et al. 2001; Lai et al. 2001; Pavlopoulos et al. 2001; Yeh et al. 2001; Glittenberg et al. 2006) and Mind bomb (Mib) (Lai et al. 2005; Le Borgne et al. 2005; Pitsouli and Delidakis 2005; Wang and Struhl 2005). The machinery is conserved in vertebrates (Deblandre et al. 2001), in which Mib was initially identified (Itoh et al. 2003). Dl and Ser endocytosis is driven by interaction of the ubiquitinated ligands with the endocytic adaptor protein epsin/liquid facets (Lqf), and loss of epsin blocks Notch signal transduction (Overstreet et al. 2003; Tian et al. 2004; Wang and Struhl 2004, 2005). Drosophila Notch is present on the cell membrane as a precleaved heterodimer (Blaumueller et al. 1997; Pan and Rubin 1997). In addition to a role in ligand presentation discussed above, endocytosis is required again following interaction of the extracellular domain with the Notch receptor on the adjacent cell (Fig. 3). Internalization of the DSL ligands into the presenting cells leads to trans-endocytosis of the Notch extracellular domain into the ligand-presenting cell (Parks et al. 2000).

This also holds true for vertebrate Notch receptors, in which the function of ligand endocytosis following receptor interaction has mainly been studied in cell culture systems (Musse et al. 2012). Supporting a hypothesis from Drosophila (Parks et al. 2000), the internalization of bound ligand physically dissociates the Notch heterodimer, thereby unmasking the $\$ 2$ cleavage site that is normally protected by the tertiary structure of the extracellular domain. Cleavage at $\mathrm{S} 2$ by membrane-associated metalloproteases then primes the Notch receptor for the subsequent cleavage by the intramembrane protease Presenilin that releases the transcriptionally active, intracellular carboxyl terminus $\left(\mathrm{N}_{\text {intra }}\right)$ (Fig. 3) (Nichols et al. 2007). This hypothesis has recently gained support through in vitro experiments in which the forces that are generated by endocytosis and required to dissociate Notch were independently measured using optic tweezer-based biophysical approaches (Meloty-Kapella et al. 2012; Shergill et al. 2012). Ubiquitination and endocytosis of the DSL ligands within the secreting cells have also been co-opted as targets for the tissue-specific regulation of Notch signaling. In flies, members of the Bearded protein family competitively inhibit the interaction of $\mathrm{Dl}$ and $\mathrm{Neu}$, prevent ligand ubiquitination, and thus down-regulate Notch signaling in adjacent cells (Bardin and Schweisguth 2006; De Renzis et al. 2006; Fontana and Posakony 2009). In addition, both in flies and vertebrates, the Mib ubiquitin ligase can be inactivated in a tissue-specific manner through phosphorylation by Par-1, again suppressing DSL ligand endocytosis (Bayraktar et al. 2006; Ossipova et al. 2009). 


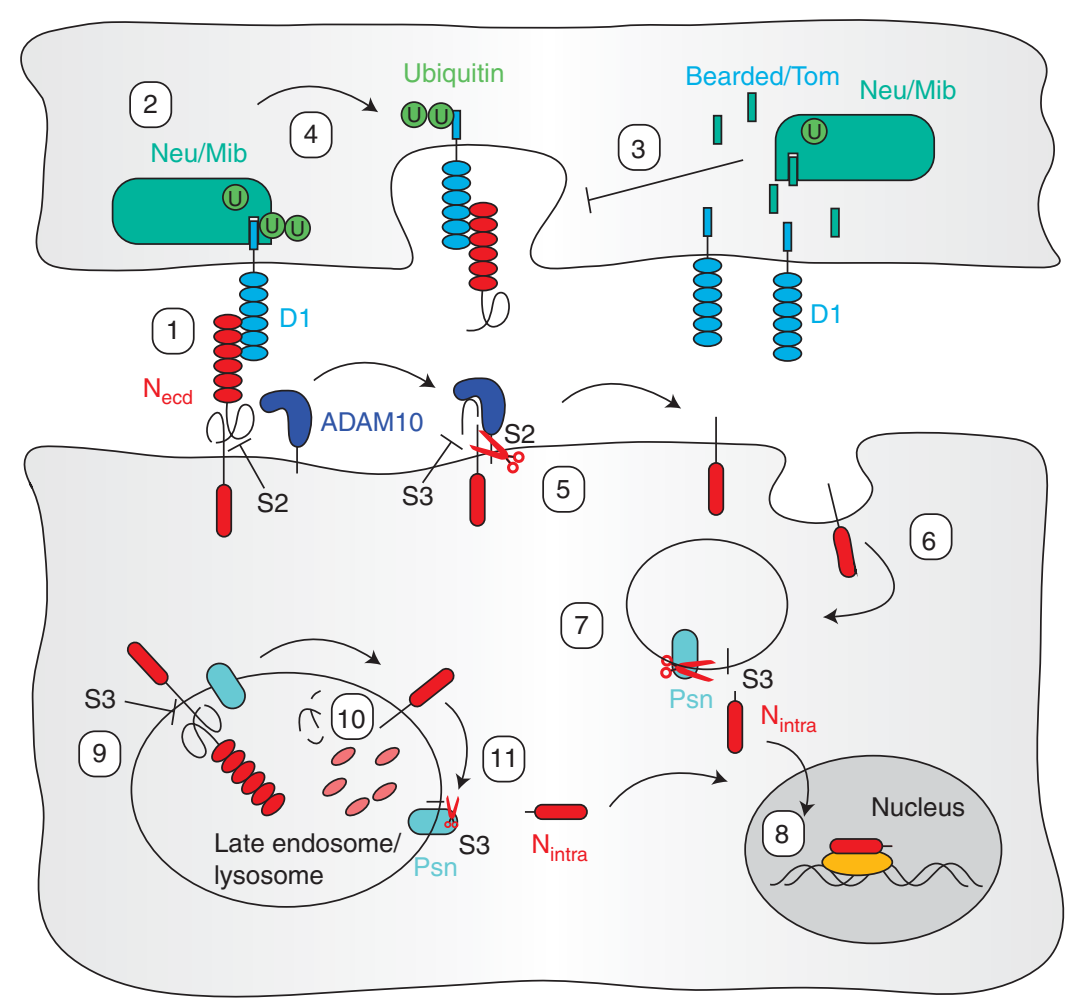

Figure 3. Endocytosis and activation of the Notch $(\mathrm{N})$ pathway. The precleaved transmembrane receptor Notch binds to its transmembrane ligand Delta (Dl, blue) on the adjacent cell (1). Conformation of the membrane proximal region of the Notch extracellular domain $\left(\mathrm{N}_{\mathrm{ecd}}\right.$, red) prevents cleavage at the $\mathrm{S} 2$ site by the metalloprotease ADAM10. In the ligand-presenting cell, Dl is ubiquitinated by the E3 ligases Neuralized (Neu) or Mind bomb (Mib, green). This step can be competitively inhibited by members of the Bearded protein family that mimic the $\mathrm{Dl}$ intracellular domain (3). Ubiquitination drives Dl internalization and trans-endocytosis of $\mathrm{N}_{\text {ecd }}$ (4), which unmasks the S2 cleavage site (5). This facilitates internalization to endosomes (6) in which cleavage at the $\mathrm{S} 3$ site by Presenilin (Psn) and thus release of $\mathrm{N}_{\text {intra }}$ occurs (7). $\mathrm{N}_{\text {intra }}$ can then enter the nucleus to direct target gene expression (8). Ligand-independent activation occurs by trafficking of Notch to the endosomal or lysosomal limiting membrane in the secreting cell (9). Proetolytic degradation of $\mathrm{N}_{\text {ecd }}$ (10) again facilitates S3 cleavage (11) and nuclear translocation of $\mathrm{N}_{\text {intra }}$.

However, endocytosis is also involved in Notch pathway modulation in the signal-receiving cells. The E3 ubiquitin ligase Deltex (Dx) promotes internalization of Notch and its trafficking toward multivesicular, late endosomes and lysosomes in an AP3 and HOPS complexdependent manner (Hori et al. 2004; Wilkin et al. 2008). As expected, this trafficking can cause Notch degradation and thus down-regulate the ability of the cell to receive the Notch signal. However, Dx- and AP3-mediated sorting of Notch to the lysosomal limiting membrane can also promote Notch signaling (Wilkin et al. 2008). Sorting between limiting membrane and internal vesicles involves Dx as well as Shrub, a core component of the ESCRT-III complex (Hori et al. 2011) and its C2 and DM14 domain-containing binding partner Lethal (2) giant discs (Lgd) (Troost et al. 2012). Degradation of the Notch extracellular domain is thought to provide the priming function for the Psn-mediated release of the Notch intracellular domain (Hori et al. 2011; Schneider et al. 2013). Endosomal Notch activation is therefore ligand independent. This pathway may also play a role in biasing Notch signaling to the pIIa cell 
during sensory organ development in the fly pupa. In the SOP cells, both Notch and Dl can be found within endosomes positive for the FYVE domain adaptor protein Sara already, before mitosis. During the asymmetric SOP divisions, these endosomes are preferentially segregated to the pIIa cells where they contribute to the increased Notch activation level relative to the pIIb cells (Coumailleau et al. 2009).

Endocytosis also acts in the signal-receiving cells during the initial activation steps of several other pathways. During the specification of polar cell fates in the Drosophila follicle epithelium, Jak/Stat signaling through the cytokinelike ligand Unpaired (Upd) and its receptor domeless (Dome) requires both clathrin-mediated endocytosis into Rab5- and PI(3)P-positive early endosomes and onward intracellular trafficking toward lysosomes. Consequently, inactivation of either the clathrin heavy chain Rab5, the ESCRT-0 component Hrs, or the lysosomal maturation factor Deep orange (Dor), the homolog of yeast Vps18p, block Jak/Stat pathway activation downstream from Dome (Devergne et al. 2007). However, these experiments shed no light on the cell biological role of endocytosis in cytokine receptor signaling, which is triggered by ligand-induced receptor dimerization that bring the associated Jak kinases into sufficient proximity for cross-activation (Leonard and O'Shea 1998). Instead, work on the mammalian interleukin-4 receptor using microscopy-based biophysical methods recently revealed that the lateral affinities governing ligand-induced receptor complex dimerization are too low for productive complex formation under physiological conditions. Signaling thus requires a subcellular concentration step, which is provided by endocytosis into a cortical, actinassociated subpopulation of early endosomes (C Bökel and T Weidemann, pers. comm.). Unlike the scaffolding role of signaling endosomes seen in other signaling pathways that facilitate interaction of preactivated receptors with downstream signaling components (Sadowski et al. 2009; Platta and Stenmark 2011), endocytosis in the IL-4 system fulfills an essential, thermodynamic role already at the first step of pathway activation following ligand binding.
In addition to promoting signal transduction following ligand binding, endocytosis may be used by the cell to keep signaling pathways in the off state in the absence of ligand. For example, the GPCR-like protein Smoothened (Smo), the key transducer of Drosophila Hedgehog $(\mathrm{Hh})$ signaling cascade, is retained on intracellular membranes (Denef et al. 2000; Zhu et al. 2003; Nakano et al. 2004), presumably a mixture of early and late endosomes and lysosomes (Nakano et al. 2004; Li et al. 2012; Xia et al. 2012), through some as-yet poorly defined activity of the Hh receptor Patched (Ptc). When $\mathrm{Hh}$ binding represses this inhibitory activity of Ptc, Smo becomes phosphorylated by PKA and CK1 (Jia et al. 2004; Zhang et al. 2004; Apionishev et al. 2005) translocates to the plasma membrane (Denef et al. 2000; Zhu et al. 2003; Nakano et al. 2004). Phosphorylation also induces a conformational change of the Smo cytoplasmic tail and the formation of Smo clusters in the plasma membrane (Zhao et al. 2007). Phosphorylation contributes to the redistribution of Smo from the endosomes to the cell surface by preventing the ubiquitination of adjacent lysine residues that would promote Smo endocytosis ( $\mathrm{Li}$ et al. 2012) and via the recruitment of the deubiquitinating enzyme USP8 (Xia et al. 2012). However, Hh pathway activity appears to be also controlled by local membrane lipid composition. Ptc inactivation increases phosphatidyl-inositol-4-phosphate (PI4P) levels. Lipid modification acts upstream of Hh pathway activation, as loss of Sac1, a PI4P phosphatase, activates the pathway, whereas inactivation of STT4, a lipid kinase required for PI4P synthesis, blocks Hh signaling (Yavari et al. 2010). A role of potentially lipid-mediated protein trafficking in regulating $\mathrm{Hh}$ signal transduction was also shown by tracking Smo phosphorylation at the subcellular level. Using a fluorescence-based reporter for Smo activation, it could be shown that retention at the plasma membrane is sufficient to drive Smo phosphorylation in the absence of Hh. Conversely, fluorescence cross-correlation measurements show that inactivation of Ptc by $\mathrm{Hh}$ causes Smo clustering even in the absence of phosphorylation (Kupinski et al. 2012). 


\section{SIGNALING ENDOSOMES AND INTRACELLULAR REGULATION OF SIGNAL TRANSDUCTION}

In recent years, examples for signal transduction following the trafficking of preactivated receptors to specific endosomes have been identified in several molecularly unrelated pathways (Miaczynska et al. 2004; Sadowski et al. 2009; Platta and Stenmark 2011). In this final section we will discuss a few selected examples that illustrate the importance of endosomes for the spatial and temporal modulation of signaling in development.

Both in vertebrates and flies, TGF- $\beta$ family growth factors belonging to both the BMP and Nodal/activin subfamilies organize the longrange patterning of developing tissues. In the Drosophila larval wing disc, the Dpp morphogen gradient discussed above gives rise to a receptor activation gradient (Michel et al. 2011) and subsequently a transcription factor activation gradient that defines the position of the cell relative to the source. As shown for the related activin pathway in Xenopus (Bourillot et al. 2002) correct interpretation of the Dpp gradient is thought to depend on continuous signal-transduction flow. To maintain gradient smoothness in a growing tissue it is therefore important that during cell division activated pathway components are evenly distributed between sibling cells, even if these differ in size owing to geometrical constraints. In the fly, this is achieved with the help of Sara-positive early endosomes that contain the Dpp receptor $\mathrm{Tkv}$ and are recruited onto the central spindle from which they are evenly distributed into the daughter cells (Bökel et al. 2006). In the activin pathway Sara in addition serves as an adaptor that presents the Smad2/3 R-Smad transcription factors to the activated activin receptors. Because Sara is localized to early endosomes via its FYVE domain, Smad presentation requires prior internalization of receptors activated at the membrane to the Sara-positive endosomes, from which downstream signaling then occurs (Tsukazaki et al. 1998). Retention of activated receptors at Sara endosomes may also underlie the phenomenon of cellular memory observed in TGF- $\beta$ /activin signal transduction (Jullien and Gurdon 2005). In a developmental context, this could buffer the cells against shortterm fluctuations in extracellular ligand concentrations and allow the temporal integration of weak signals.

Signal transduction from an intermediate, signaling-competent, endocytic compartment also contributes to zebrafish FGF signaling. The activity of the E3 ubiquitin ligase Cbl controls the trafficking of activated FGF receptors and acts as an RTK endocytosis adaptor independent of its enzymatic function (Soubeyran et al. 2002; Haugsten et al. 2008). Overexpression of a $\mathrm{Cbl}$ version lacking enzymatic activity but retaining the adaptor function increases pathway activity by delaying the sorting of the activated FGF receptors from a signaling-competent compartment toward the degradatory pathway (Nowak et al. 2011). Although endocytosis is also involved in shaping the gradient (Scholpp and Brand 2004; Yu et al. 2009), Cblmediated endocytic sorting does not affect gradient shape as such. It therefore represents an independent, additional tier of regulation that allows target cells to choose how to interpret a given ambient ligand concentration.

Endosomal localization may also be used to determine signal specificity toward different downstream pathway effectors. In the zebrafish embryo, activated Akt kinase is recruited to a subset of Rab5-positive early endosomes by APPL1, where it selectively phosphorylates GSK-3 $\beta$ but not an alternative substrate, the GTPase-activating protein TSC2 (Schenck et al. 2008).

Finally, endosomes may influence signal transduction by sequestering activated receptors from the cytoplasm. Although in many cases this leads to signal termination, in the Wnt pathway receptor, sequestration drives pathway activation. Internalization of Wnt ligands and the Frizzled and LRP5/6 receptor components by both clathrin- (Blitzer and Nusse 2006) and caveolin-mediated endocytosis (Yamamoto et al. 2006; Bilic et al. 2007) has been reported to be required for Wnt signal transduction. Following endocytosis, the activated complexes form large, phospho-LRP-associated signalo- 
somes that also contain other signaling molecules such as Axin, Disshevelled, and GSK-3. These signalosomes are then sorted onto internal vesicles of multivesicular endosomes (Bilic et al. 2007; Metcalfe et al. 2010). This sequesters the associated proteins from the cytoplasm, thus preventing the GSK-3-mediated phosphorylation and destabilization of $\beta$-catenin. Consequently, inactivation of the ESCRT complex member Hrs or the ATPase Vps4, which are required for MVB formation, prevents Wnt signaling in the Xenopus embryo (Taelman et al. 2010). However, in the fly embryo, trafficking of the Wnt signaling complexes to the late endosome/lysosome is instead required for pathway down-regulation (Dubois et al. 2001).

\section{THE ZEBRAFISH AS A MODEL ORGANISM FOR IMAGING DRIVEN CELL BIOLOGY}

Breaking biological questions arising at organ or tissue levels down to their cell biological basis has long been the specialty of invertebrate model organisms such as Drosophila, largely owing to their experimental convenience and the established genetic toolkits. However, with the establishment of the zebrafish as a model system vertebrates are quickly catching up. The zebrafish develops from a fertilized egg to a larva that possesses all organ systems characteristic of the vertebrate body plan within roughly $24 \mathrm{~h}$, and hatches in the laboratory as a free swimming, active animal within $48-72 \mathrm{~h}$ after fertilization. In addition, zebrafish embryos and larvae are largely optically transparent (Nüsslein-Volhard and Dahm 2002). Recent years have therefore seen a wealth of microscopic approaches to cell biology implemented in the zebrafish system. An early example of this approach in zebrafish is the demonstration that endocytosis, as visualized and manipulated via the activity state of Rab5, controls spreading and effective signaling range of Fgf- 8 protein in the early neural plate (Scholpp and Brand 2004). More recently, the Brainbow technology originally developed for the murine CNS (Livet et al. 2007) is now also available for multicolor cell tracking in fish (Pan et al. 2013), where live imaging of developmental processes is much easier owing to its external development. Similarly, systematic approaches are under way to generate transcriptional reporters for signaling pathway activation (Moro et al. 2013; Xiong et al. 2013) or to tag zebrafish Rab GTPases with fluorescent proteins using a modular expression system (Clark et al. 2011), complementing previous efforts in Drosophila (Chan et al. 2011). Such fluorescently tagged Rab proteins can be combined with labeled cargo proteins to quantitatively assess trafficking of cargo molecules such as FGF growth factors through the endocytic pathway (Nowak et al. 2011), which is greatly aided by automated image analysis. Activation state-specific reporters developed in the fly system for signal-transduction components such as BMP receptors can in principle also be transferred to the zebrafish (Michel et al. 2011). Although the above approaches can be pursued via standard confocal or multiphoton microscopy, organism scale analysis of cell behavior benefits greatly from novel microscopic technologies such as light sheet microscopy (Keller et al. 2010; Huisken 2012). Conversely, the optical properties of the fish embryo and larva allow the application of microscope-based biophysical approaches such as fluorescence correlation spectroscopy (Ries et al. 2009; Shi et al. 2009; Yu et al. 2009) or TIRF-based single molecule tracking (Schaaf et al. 2009) in intact embryos or larvae. This allows, for the first time, true in vivo determination of cell biological parameters such as diffusion rates or ligand affinities in an undisturbed tissue environment of a developing vertebrate.

\section{CONCLUDING REMARKS AND FUTURE DIRECTIONS}

The above examples illustrate the promise offered by the further integration of the still-toooften disparate research agendas of developmental and cell biology. We believe that both fields could clearly benefit from the mutual insights, and we would like to close with a brief "to-do list" for both disciplines.

Cell biologists may in the future want to increasingly appreciate the complexity of the signaling environment that governs the behavior of the cells they study. This complexity in- 
cludes not only the organization of the signaling cascades themselves but also their regulation at the cell biological level. Both must be taken into account in an organismal context. In addition to and beyond the established cell culture systems, signal transduction should therefore increasingly be studied in vivo, focusing on specific cell types in their natural environments within a developing model organism.

Conversely, developmental biology can only gain from studying how morphogen gradient formation and interpretation is implemented at the subcellular level. Studying morphogenetic pattern formation at the level of expression patterns of ligands, receptors, and target genes will in the long run not be enough. To fully understand how developmental signals are generated, processed, and interpreted to eventually generate morphogenetic information, the role of cell biological processes such as endocytosis and subcellular trafficking as rheostats of signal transduction must be increasingly taken into account.

\section{REFERENCES \\ ${ }^{*}$ Reference is also in this collection.}

Adell T, Salo E, Boutros M, Bartscherer K. 2009. Smed-Evi/ Wntless is required for $\beta$-catenin-dependent and -independent processes during planarian regeneration. Development 136: 905-910.

Apionishev S, Katanayeva NM, Marks SA, Kalderon D, Tomlinson A. 2005. Drosophila Smoothened phosphorylation sites essential for Hedgehog signal transduction. Nat Cell Biol 7: 86-92.

Banks SM, Cho B, Eun SH, Lee JH, Windler SL, Xie X, Bilder D, Fischer JA. 2011. The functions of auxilin and Rab11 in Drosophila suggest that the fundamental role of ligand endocytosis in notch signaling cells is not recycling. PLoS ONE 6: e18259.

Banziger C, Soldini D, Schutt C, Zipperlen P, Hausmann G, Basler K. 2006. Wntless, a conserved membrane protein dedicated to the secretion of Wnt proteins from signaling cells. Cell 125: 509-522.

Bardin AJ, Schweisguth F. 2006. Bearded family members inhibit Neuralized-mediated endocytosis and signaling activity of Delta in Drosophila. Dev Cell 10: 245-255.

Bartscherer K, Pelte N, Ingelfinger D, Boutros M. 2006. Secretion of Wnt ligands requires Evi, a conserved transmembrane protein. Cell 125: 523-533.

Bayraktar J, Zygmunt D, Carthew RW. 2006. Par-1 kinase establishes cell polarity and functions in Notch signaling in the Drosophila embryo. J Cell Sci 119: 711721.
Beckett K, Monier S, Palmer L, Alexandre C, Green H, Bonneil E, Raposo G, Thibault P, Le Borgne R, Vincent JP. 2013. Drosophila S2 cells secrete wingless on exosomelike vesicles but the wingless gradient forms independently of exosomes. Traffic 14: 82-96.

Belenkaya TY, Wu Y, Tang X, Zhou B, Cheng L, Sharma YV, Yan D, Selva EM, Lin X. 2008. The retromer complex influences Wnt secretion by recycling wntless from endosomes to the trans-Golgi network. Dev Cell 14: 120131.

Benhra N, Vignaux F, Dussert A, Schweisguth F, Le Borgne R. 2010. Neuralized promotes basal to apical transcytosis of Delta in epithelial cells. Mol Biol Cell 21: 2078-2086.

Ben-Shlomo I, Yu Hsu S, Rauch R, Kowalski HW, Hsueh AJ. 2003. Signaling receptome: A genomic and evolutionary perspective of plasma membrane receptors involved in signal transduction. Sci STKE 2003: re9.

Bilic J, Huang YL, Davidson G, Zimmermann T, Cruciat CM, Bienz M, Niehrs C. 2007. Wnt induces LRP6 signalosomes and promotes dishevelled-dependent LRP6 phosphorylation. Science (New York, NY) 316: 16191622.

Blankenship JT, Fuller MT, Zallen JA. 2007. The Drosophila homolog of the Exo84 exocyst subunit promotes apical epithelial identity. J Cell Sci 120: 3099-3110.

Blaumueller CM, Qi H, Zagouras P, Artavanis-Tsakonas S. 1997. Intracellular cleavage of Notch leads to a heterodimeric receptor on the plasma membrane. Cell 90: 281 291.

Blitzer JT, Nusse R. 2006. A critical role for endocytosis in Wnt signaling. BMC Cell Biol 7: 28.

Bökel C, Brand M. 2013. Generation and interpretation of FGF morphogen gradients in vertebrates. Curr Opin Gen Dev 23: 415-422.

Bökel C, Schwabedissen A, Entchev E, Renaud O, GonzálezGaitán M. 2006. Sara endosomes and the maintenance of Dpp signaling levels across mitosis. Science 314: 11351139.

Boldajipour B, Mahabaleshwar H, Kardash E, ReichmanFried M, Blaser H, Minina S, Wilson D, Xu Q, Raz E. 2008. Control of chemokine-guided cell migration by ligand sequestration. Cell 132: 463-473.

Bollenbach T, Pantazis P, Kicheva A, Bökel C, GonzalezGaitan M, Jülicher F. 2008. Precision of the Dpp gradient. Development 135: 1137-1146.

Bourillot PY, Garrett N, Gurdon JB. 2002. A changing morphogen gradient is interpreted by continuous transduction flow. Development 129: 2167-2180.

Chan CC, Scoggin S, Wang D, Cherry S, Dembo T, Greenberg B, Jin EJ, Kuey C, Lopez A, Mehta SQ, et al. 2011. Systematic discovery of Rab GTPases with synaptic functions in Drosophila. Curr Biol 21: 1704-1715.

Clark BS, Winter M, Cohen AR, Link BA. 2011. Generation of Rab-based transgenic lines for in vivo studies of endosome biology in zebrafish. Dev Dyn 240: 2452-2465.

Coudreuse DY, Roel G, Betist MC, Destree O, Korswagen HC. 2006. Wnt gradient formation requires retromer function in Wnt-producing cells. Science (New York, NY) 312: 921-924.

Coumailleau F, Fürthauer M, Knoblich JA, González-Gaitán M. 2009. Directional Delta and Notch trafficking in Sara 
endosomes during asymmetric cell division. Nature 458: $1051-1055$.

Crick F. 1970. Diffusion in embryogenesis. Nature 225: 420-422.

Deblandre GA, Lai EC, Kintner C. 2001. Xenopus neuralized is a ubiquitin ligase that interacts with XDelta1 and regulates Notch signaling. Dev Cell 1: 795-806.

Denef N, Neubuser D, Perez L, Cohen SM. 2000. Hedgehog induces opposite changes in turnover and subcellular localization of patched and smoothened. Cell 102: $521-531$.

De Renzis S, Yu J, Zinzen R, Wieschaus E. 2006. Dorsalventral pattern of Delta trafficking is established by a Snail-Tom-Neuralized pathway. Dev Cell 10: 257-264.

Devergne O, Ghiglione C, Noselli S. 2007. The endocytic control of JAK/STAT signalling in Drosophila. J Cell Sci 120: $3457-3464$.

Doitsidou M, Reichman-Fried M, Stebler J, Koprunner M, Dorries J, Meyer D, Esguerra CV, Leung T, Raz E. 2002. Guidance of primordial germ-cell migration by the chemokine SDF-1. Cell 111: 647-659.

Dubois L, Lecourtois M, Alexandre C, Hirst E, Vincent JP. 2001. Regulated endocytic routing modulates wingless signaling in Drosophila embryos. Cell 105: 613-624.

Emery G, Hutterer A, Berdnik D, Mayer B, Wirtz-Peitz F, Gaitan MG, Knoblich JA. 2005. Asymmetric Rab 11 endosomes regulate Delta recycling and specify cell fate in the Drosophila nervous system. Cell 122: 763-773.

Entchev EV, Schwabedissen A, González-Gaitán M. 2000. Gradient formation of the TGF- $\beta$ homolog Dpp. Cell 103: 981-991.

Fontana JR, Posakony JW. 2009. Both inhibition and activation of Notch signaling rely on a conserved Neuralizedbinding motif in Bearded proteins and the Notch ligand Delta. Dev Biol 333: 373-385.

Franch-Marro X, Wendler F, Guidato S, Griffith J, BaenaLopez A, Itasaki N, Maurice MM, Vincent JP. 2008. Wingless secretion requires endosome-to-Golgi retrieval of Wntless/Evi/Sprinter by the retromer complex. Nat Cell Biol 10: 170-177.

Fu J, Jiang M, Mirando AJ, Yu HM, Hsu W. 2009. Reciprocal regulation of Wnt and Gpr177/mouse Wntless is required for embryonic axis formation. Proc Natl Acad Sci 106: $18598-18603$.

Fürthauer M, Thisse C, Thisse B. 1997. A role for FGF-8 in the dorsoventral patterning of the zebrafish gastrula. Development 124: 4253-4264.

Gasnereau I, Herr P, Chia PZ, Basler K, Gleeson PA. 2011. Identification of an endocytosis motif in an intracellular loop of Wntless protein, essential for its recycling and the control of Wnt protein signaling. J Biol Chem 286: 43324-43333.

Glittenberg M, Pitsouli C, Garvey C, Delidakis C, Bray S. 2006. Role of conserved intracellular motifs in Serrate signalling, cis-inhibition and endocytosis. $E M B O J$ 25: 4697-4706.

* Gonzalez-Gaitan M, Jülicher F. 2014. The role of endocytosis during morphogenetic signaling. Cold Spring Harb Perspect Biol doi: 10.1101/cshperspect.a016881.

Goodman RM, Thombre S, Firtina Z, Gray D, Betts D, Roebuck J, Spana EP, Selva EM. 2006. Sprinter: A novel trans- membrane protein required for $\mathrm{Wg}$ secretion and signaling. Development 133: 4901-4911.

Greco V, Hannus M, Eaton S. 2001. Argosomes: A potential vehicle for the spread of morphogens through epithelia. Cell 106: 633-645.

Gross JC, Chaudhary V, Bartscherer K, Boutros M. 2012. Active Wnt proteins are secreted on exosomes. Nat Cell Biol 14: 1036-1045.

Harterink M, Port F, Lorenowicz MJ, McGough IJ, Silhankova M, Betist MC, van Weering JR, van Heesbeen RG, Middelkoop TC, Basler K, et al. 2011. A SNX3-dependent retromer pathway mediates retrograde transport of the Wnt sorting receptor Wntless and is required for Wnt secretion. Nat Cell Biol 13: 914-923.

Haugsten EM, Malecki J, Bjorklund SM, Olsnes S, Wesche J. 2008. Ubiquitination of fibroblast growth factor receptor 1 is required for its intracellular sorting but not for its endocytosis. Mol Biol Cell 19: 3390-3403.

He B, Guo W. 2009. The exocyst complex in polarized exocytosis. Curr Opin Cell Biol 21: 537-542.

Hori K, Fostier M, Ito M, Fuwa TJ, Go MJ, Okano H, Baron M, Matsuno K. 2004. Drosophila deltex mediates suppressor of Hairless-independent and late-endosomal activation of Notch signaling. Development 131: $5527-$ 5537.

Hori K, Sen A, Kirchhausen T, Artavanis-Tsakonas S. 2011. Synergy between the ESCRT-III complex and Deltex defines a ligand-independent Notch signal. J Cell Biol 195: 1005-1015.

Hsiung F, Ramirez-Weber FA, Iwaki DD, Kornberg TB. 2005. Dependence of Drosophila wing imaginal disc cytonemes on Decapentaplegic. Nature 437: 560-563.

Huisken J. 2012. Slicing embryos gently with laser light sheets. Bioessays 34: 406-411.

Itoh M, Kim CH, Palardy G, Oda T, Jiang YJ, Maust D, Yeo SY, Lorick K, Wright GJ, Ariza-McNaughton L, et al. 2003. Mind bomb is a ubiquitin ligase that is essential for efficient activation of Notch signaling by Delta. Dev Cell 4: 67-82.

Jia J, Tong C, Wang B, Luo L, Jiang J. 2004. Hedgehog signalling activity of Smoothened requires phosphorylation by protein kinase A and casein kinase I. Nature 432: 10451050.

Jullien J, Gurdon J. 2005. Morphogen gradient interpretation by a regulated trafficking step during ligand-receptor transduction. Genes Dev 19: 2682-2694.

Kaiser D. 2001. Building a multicellular organism. Annu Rev Genet 35: 103-123.

Keller PJ, Schmidt AD, Santella A, Khairy K, Bao Z, Wittbrodt J, Stelzer EH. 2010. Fast, high-contrast imaging of animal development with scanned light sheet-based structured-illumination microscopy. Nat Methods 7: 637-642.

Kicheva A, Pantazis P, Bollenbach T, Kalaidzidis Y, Bittig T, Jülicher F, Gonzalez-Gaitan M. 2007. Kinetics of morphogen gradient formation. Science (New York, NY) 315: $521-525$.

Kim H, Cheong SM, Ryu J, Jung HJ, Jho EH, Han JK. 2009. Xenopus Wntless and the retromer complex cooperate to regulate XWnt4 secretion. Mol Cell Biol 29: 2118-2128. 
C. Bökel and M. Brand

Knaut H, Werz C, Geisler R, Nusslein-Volhard C. 2003. A zebrafish homologue of the chemokine receptor Cxcr4 is a germ-cell guidance receptor. Nature 421: 279-282.

Koles K, Nunnari J, Korkut C, Barria R, Brewer C, Li Y, Leszyk J, Zhang B, Budnik V. 2012. Mechanism of evenness interrupted (Evi)-exosome release at synaptic boutons. J Biol Chem 287: 16820-16834.

Korkut C, Ataman B, Ramachandran P, Ashley J, Barria R, Gherbesi N, Budnik V. 2009. Trans-synaptic transmission of vesicular Wnt signals through Evi/Wntless. Cell 139: 393-404.

Kupinski AP, Raabe I, Michel M, Ail D, Brusch L, Weidemann T, Bökel C. 2013. Visualizing Smoothened phosphorylation and clustering in vivo. J Cell Sci 126: $4648-4697$.

Lai EC, Deblandre GA, Kintner C, Rubin GM. 2001. Drosophila neuralized is a ubiquitin ligase that promotes the internalization and degradation of Delta. Dev Cell 1: 783-794.

Lai EC, Roegiers F, Qin X, Jan YN, Rubin GM. 2005. The ubiquitin ligase Drosophila Mind bomb promotes Notch signaling by regulating the localization and activity of Serrate and Delta. Development 132: 2319-2332.

Langevin J, Morgan MJ, Sibarita JB, Aresta S, Murthy M, Schwarz T, Camonis J, Bellaiche Y. 2005. Drosophila exocyst components Sec5, Sec6, and Sec15 regulate DE-Cadherin trafficking from recycling endosomes to the plasma membrane. Dev Cell 9: 365-376.

Le Borgne R, Remaud S, Hamel S, Schweisguth F. 2005. Two distinct E3 ubiquitin ligases have complementary functions in the regulation of Delta and serrate signaling in Drosophila. PLoS Biol 3: e96.

Lecuit T, Brook WJ, Ng M, Calleja M, Sun H, Cohen SM. 1996. Two distinct mechanisms for long-range patterning by Decapentaplegic in the Drosophila wing. Nature 381: 387-393.

Lee JR, Urban S, Garvey CF, Freeman M. 2001. Regulated intracellular ligand transport and proteolysis control EGF signal activation in Drosophila. Cell 107: 161-171.

Leonard WJ, O'Shea JJ. 1998. Jaks and STATs: Biological implications. Annu Rev Immunol 16: 293-322.

Li S, Chen Y, Shi Q, Yue T, Wang B, Jiang J. 2012. Hedgehogregulated ubiquitination controls smoothened trafficking and cell surface expression in Drosophila. PLoS Biol 10: e1001239.

Livet J, Weissman TA, Kang H, Draft RW, Lu J, Bennis RA, Sanes JR, Lichtman JW. 2007. Transgenic strategies for combinatorial expression of fluorescent proteins in the nervous system. Nature 450: 56-62.

Losick VP, Morris LX, Fox DT, Spradling A. 2011. Drosophila stem cell niches: A decade of discovery suggests a unified view of stem cell regulation. Dev Cell 21: 159-171.

Mahabaleshwar H, Tarbashevich K, Nowak M, Brand M, Raz E. 2012. $\beta$-Arrestin control of late endosomal sorting facilitates decoy receptor function and chemokine gradient formation. Development 139: 2897-2902.

Meloty-Kapella L, Shergill B, Kuon J, Botvinick E, Weinmaster G. 2012. Notch ligand endocytosis generates mechanical pulling force dependent on dynamin, epsins, and actin. Dev Cell 22: 1299-1312.
Metcalfe C, Mendoza-Topaz C, Mieszczanek J, Bienz M. 2010. Stability elements in the LRP6 cytoplasmic tail confer efficient signalling upon DIX-dependent polymerization. J Cell Sci 123: 1588-1599.

Miaczynska M, Bar-Sagi D. 2010. Signaling endosomes: Seeing is believing. Curr Opin Cell Biol 22: 535-540.

Miaczynska M, Pelkmans L, Zerial M. 2004. Not just a sink: Endosomes in control of signal transduction. Curr Opin Cell Biol 16: 400-406.

Michel M, Raabe I, Kupinski AP, Perez-Palencia R, Bökel C. 2011. Local BMP receptor activation at adherens junctions in the Drosophila germline stem cell niche. Nat Commun 2: 415.

Molyneaux KA, Zinszner H, Kunwar PS, Schaible K, Stebler J, Sunshine MJ, O’Brien W, Raz E, Littman D, Wylie C, et al. 2003. The chemokine SDF1/CXCL12 and its receptor CXCR4 regulate mouse germ-cell migration and survival. Development 130: 4279-4286.

Moro E, Vettori A, Porazzi P, Schiavone M, Rampazzo E, Casari A, Ek O, Facchinello N, Astone M, Zancan I, et al. 2013. Generation and application of signaling pathway reporter lines in zebrafish. Mol Genet Genomics 288: 231-242.

Müller P, Schier AF. 2011. Extracellular movement of signaling molecules. Dev Cell 21: 145-158.

Musse AA, Meloty-Kapella L, Weinmaster G. 2012. Notch ligand endocytosis: Mechanistic basis of signaling activity. Semin Cell Dev Biol 23: 429-436.

Nakano Y, Nystedt S, Shivdasani AA, Strutt H, Thomas C, Ingham PW. 2004. Functional domains and sub-cellular distribution of the Hedgehog transducing protein Smoothened in Drosophila. Mech Dev 121: 507-518.

Nejsum LN, Nelson WJ. 2007. A molecular mechanism directly linking E-cadherin adhesion to initiation of epithelial cell surface polarity. J Cell Biol 178: 323-335.

Nellen D, Burke R, Struhl G, Basler K. 1996. Direct and longrange action of a DPP morphogen gradient. Cell 85: 357368.

Neumann CJ, Cohen SM. 1997. Long-range action of Wingless organizes the dorsal-ventral axis of the Drosophila wing. Development 124: 871-880.

Nichols JT, Miyamoto A, Olsen SL, D'Souza B, Yao C, Weinmaster G. 2007. DSL ligand endocytosis physically dissociates Notch 1 heterodimers before activating proteolysis can occur. J Cell Biol 176: 445-458.

Nowak M, Machate A, Yu SR, Gupta M, Brand M. 2011. Interpretation of the FGF8 morphogen gradient is regulated by endocytic trafficking. Nat Cell Biol 13: 153-158.

Nüsslein-Volhard C, Dahm R. 2002. Zebrafish. Oxford University Press, Oxford.

Ossipova O, Ezan J, Sokol SY. 2009. PAR-1 phosphorylates Mind bomb to promote vertebrate neurogenesis. Dev Cell 17: $222-233$.

Overstreet E, Chen X, Wendland B, Fischer JA. 2003. Either part of a Drosophila epsin protein, divided after the ENTH domain, functions in endocytosis of Delta in the developing eye. Curr Biol 13: 854-860.

Pan D, Rubin GM. 1997. Kuzbanian controls proteolytic processing of Notch and mediates lateral inhibition during Drosophila and vertebrate neurogenesis. Cell 90: $271-280$. 
Pan CL, Baum PD, Gu M, Jorgensen EM, Clark SG, Garriga G. 2008. C. elegans AP2 and retromer control Wnt signaling by regulating mig-14/Wntless. Dev Cell 14: 132139.

Pan YA, Freundlich T, Weissman TA, Schoppik D, Wang XC, Zimmerman S, Ciruna B, Sanes JR, Lichtman JW, Schier AF. 2013. Zebrabow: Multispectral cell labeling for cell tracing and lineage analysis in zebrafish. Development 140: $2835-2846$.

Parks AL, Klueg KM, Stout JR, Muskavitch MA. 2000. Ligand endocytosis drives receptor dissociation and activation in the Notch pathway. Development 127: 1373-1385.

Pavlopoulos E, Pitsouli C, Klueg KM, Muskavitch MA, Moschonas NK, Delidakis C. 2001. neuralized Encodes a peripheral membrane protein involved in Delta signaling and endocytosis. Dev Cell 1: 807-816.

Perrimon N, Pitsouli C, Shilo BZ. 2012. Signaling mechanisms controlling cell fate and embryonic patterning. Cold Spring Harb Perspect Biol 4: a005975.

Pires-daSilva A, Sommer RJ. 2003. The evolution of signalling pathways in animal development. Nat Rev Genet 4: 39-49.

Pitsouli C, Delidakis C. 2005. The interplay between DSL proteins and ubiquitin ligases in Notch signaling. Development 132: 4041-4050.

Platta HW, Stenmark H. 2011. Endocytosis and signaling. Curr Opin Cell Biol 23: 393-403.

Port F, Basler K. 2010. Wnt trafficking: New insights into Wnt maturation, secretion and spreading. Traffic 11: $1265-1271$.

Port F, Kuster M, Herr P, Furger E, Banziger C, Hausmann G, Basler K. 2008. Wingless secretion promotes and requires retromer-dependent cycling of Wntless. Nat Cell Biol 10: $178-185$.

Prasad BC, Clark SG. 2006. Wnt signaling establishes anteroposterior neuronal polarity and requires retromer in C. elegans. Development 133: 1757-1766.

Rajan A, Tien AC, Haueter CM, Schulze KL, Bellen HJ. 2009. The Arp $2 / 3$ complex and WASp are required for apical trafficking of Delta into microvilli during cell fate specification of sensory organ precursors. Nat Cell Biol 11: 815-824.

Reifers F, Bohli H, Walsh EC, Crossley PH, Stainier DY, Brand M. 1998. Fgf8 is mutated in zebrafish acerebellar (ace) mutants and is required for maintenance of midbrain-hindbrain boundary development and somitogenesis. Development 125: 2381-2395.

Ries J, Yu SR, Burkhardt M, Brand M, Schwille P. 2009. Modular scanning FCS quantifies receptor-ligand interactions in living multicellular organisms. Nat Methods 6: 643-645.

Roy S, Hsiung F, Kornberg TB. 2011. Specificity of Drosophila cytonemes for distinct signaling pathways. Science (New York, NY) 332: 354-358.

Sadowski L, Pilecka I, Miaczynska M. 2009. Signaling from endosomes: Location makes a difference. Exp Cell Res 315: 1601-1609.

Schaaf MJ, Koopmans WJ, Meckel T, van Noort J, SnaarJagalska BE, Schmidt TS, Spaink HP. 2009. Single-molecule microscopy reveals membrane microdomain orga- nization of cells in a living vertebrate. Biophys J 97: 12061214.

Schenck A, Goto-Silva L, Collinet C, Rhinn M, Giner A, Habermann B, Brand M, Zerial M. 2008. The endosomal protein Appl1 mediates Akt substrate specificity and cell survival in vertebrate development. Cell 133: 486-497.

Schneider M, Troost T, Grawe F, Martinez-Arias A, Klein T. 2013. Activation of Notch in lgd mutant cells requires the fusion of late endosomes with the lysosome. J Cell Sci 126: 645-656.

Scholpp S, Brand M. 2004. Endocytosis controls spreading and effective signaling range of Fgf8 protein. Curr Biol 14: 1834-1841.

Schwank G, Dalessi S, Yang SF, Yagi R, de Lachapelle AM, Affolter M, Bergmann S, Basler K. 2011. Formation of the long range Dpp morphogen gradient. PLoS Biol 9: e1001111.

Seugnet L, Simpson P, Haenlin M. 1997. Requirement for dynamin during Notch signaling in Drosophila neurogenesis. Dev Biol 192: 585-598.

Shergill B, Meloty-Kapella L, Musse AA, Weinmaster G, Botvinick E. 2012. Optical tweezers studies on Notch: Single-molecule interaction strength is independent of ligand endocytosis. Dev Cell 22: 1313-1320.

Shi X, Teo LS, Pan X, Chong SW, Kraut R, Korzh V, Wohland T. 2009. Probing events with single molecule sensitivity in zebrafish and Drosophila embryos by fluorescence correlation spectroscopy. Dev Dyn 238: 3156-3167.

Soubeyran P, Kowanetz K, Szymkiewicz I, Langdon WY, Dikic I. 2002. Cbl-CIN85-endophilin complex mediates ligand-induced downregulation of EGF receptors. Nature 416: $183-187$.

Spemann H, Mangold H. 1924. Über die Induktion von Embryonalanlagen durch Implantation artfremder Organisatoren. Arch mikr Anat Entw Mech 100: 599-638.

Taelman VF, Dobrowolski R, Plouhinec JL, Fuentealba LC, Vorwald PP, Gumper I, Sabatini DD, De Robertis EM. 2010. Wnt signaling requires sequestration of glycogen synthase kinase 3 inside multivesicular endosomes. Cell 143: $1136-1148$.

Tanimoto H, Itoh S, ten Dijke P, Tabata T. 2000. Hedgehog creates a gradient of DPP activity in Drosophila wing imaginal discs. Mol Cell 5: 59-71.

Teleman AA, Cohen SM. 2000. Dpp gradient formation in the Drosophila wing imaginal disc. Cell 103: 971-980.

Tian X, Hansen D, Schedl T, Skeath JB. 2004. Epsin potentiates Notch pathway activity in Drosophila and C. elegans. Development 131: 5807-5815.

Troost T, Jaeckel S, Ohlenhard N, Klein T. 2012. The tumour suppressor Lethal (2) giant discs is required for the function of the ESCRT-III component Shrub/CHMP4. J Cell Sci 125: 763-776.

Tsruya R, Schlesinger A, Reich A, Gabay L, Sapir A, Shilo BZ. 2002. Intracellular trafficking by Star regulates cleavage of the Drosophila EGF receptor ligand Spitz. Genes Dev 16: 222-234.

Tsukazaki T, Chiang TA, Davison AF, Attisano L, Wrana JL. 1998. SARA, a FYVE domain protein that recruits $S$ mad2 to the TGF- $\beta$ receptor. Cell 95: 779-791. 
C. Bökel and M. Brand

Urban S, Lee JR, Freeman M. 2001. Drosophila rhomboid-1 defines a family of putative intramembrane serine proteases. Cell 107: 173-182.

Wang W, Struhl G. 2004. Drosophila Epsin mediates a select endocytic pathway that DSL ligands must enter to activate Notch. Development 131: 5367-5380.

Wang W, Struhl G. 2005. Distinct roles for Mind bomb Neuralized and Epsin in mediating DSL endocytosis and signaling in Drosophila. Development 132: 28832894.

Wartlick O, Kicheva A, González-Gaitán M. 2009. Morphogen gradient formation. Cold Spring Harb Perspect Biol 1: a001255.

Wilkin M, Tongngok P, Gensch N, Clemence S, Motoki M, Yamada K, Hori K, Taniguchi-Kanai M, Franklin E, Matsuno K, et al. 2008. Drosophila HOPS and AP-3 complex genes are required for a Deltex-regulated activation of notch in the endosomal trafficking pathway. Dev Cell 15: $762-772$.

Windler SL, Bilder D. 2010. Endocytic internalization routes required for Delta/Notch signaling. Curr Biol 20: $538-$ 543.

Wolpert L. 1969. Positional information and the spatial pattern of cellular differentiation. J Theor Biol 25: 1-47.

Xia R, Jia H, Fan J, Liu Y, Jia J. 2012. USP8 promotes smoothened signaling by preventing its ubiquitination and changing its subcellular localization. PLoS Biol 10: e1001238.

Xiong F, Tentner AR, Huang P, Gelas A, Mosaliganti KR, Souhait L, Rannou N, Swinburne IA, Obholzer ND, Cowgill PD, et al. 2013. Specified neural progenitors sort to form sharp domains after noisy Shh signaling. Cell 153: 550-561.

Yamamoto H, Komekado H, Kikuchi A. 2006. Caveolin is necessary for Wnt-3a-dependent internalization of LRP6 and accumulation of $\beta$-catenin. Dev Cell 11: 213-223.

Yang PT, Lorenowicz MJ, Silhankova M, Coudreuse DY, Betist MC, Korswagen HC. 2008. Wnt signaling requires retromer-dependent recycling of MIG-14/Wntless in Wnt-producing cells. Dev Cell 14: 140-147.

Yavari A, Nagaraj R, Owusu-Ansah E, Folick A, Ngo K, Hillman T, Call G, Rohatgi R, Scott MP, Banerjee U. 2010. Role of lipid metabolism in smoothened derepression in hedgehog signaling. Dev Cell 19: 54-65.

Yeh E, Dermer M, Commisso C, Zhou L, McGlade CJ, Boulianne GL. 2001. Neuralized functions as an E3 ubiquitin ligase during Drosophila development. Curr Biol 11: 1675-1679.

Yogev S, Schejter ED, Shilo BZ. 2010. Polarized secretion of Drosophila EGFR ligand from photoreceptor neurons is controlled by ER localization of the ligand-processing machinery. PLoS Biol doi: 10.1371/journal.pbio. 1000505.

Yu SR, Burkhardt M, Nowak M, Ries J, Petrasek Z, Scholpp S, Schwille P, Brand M. 2009. Fgf8 morphogen gradient forms by a source-sink mechanism with freely diffusing molecules. Nature 461: 533-536.

Zecca M, Basler K, Struhl G. 1996. Direct and long-range action of a wingless morphogen gradient. Cell 87: 833844.

Zhang C, Williams EH, Guo Y, Lum L, Beachy PA. 2004. Extensive phosphorylation of Smoothened in Hedgehog pathway activation. Proc Natl Acad Sci 101: 1790017907.

Zhang P, Wu Y, Belenkaya TY, Lin X. 2011. SNX3 controls Wingless/Wnt secretion through regulating retromer-dependent recycling of Wntless. Cell Res 21: 16771690.

Zhao Y, Tong C, Jiang J. 2007. Hedgehog regulates smoothened activity by inducing a conformational switch. $\mathrm{Na}$ ture 450: 252-258.

Zhu AJ, Zheng L, Suyama K, Scott MP. 2003. Altered localization of Drosophila Smoothened protein activates Hedgehog signal transduction. Genes Dev 17: 12401252. 


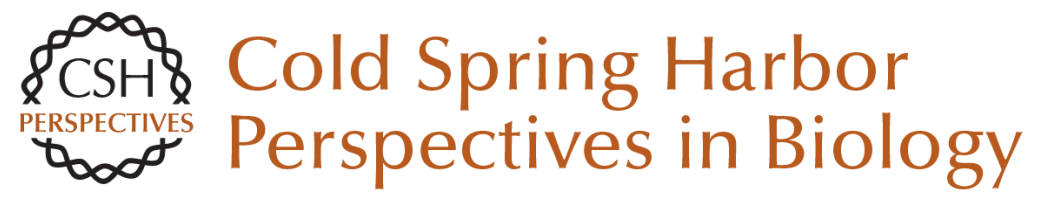

\section{Endocytosis and Signaling during Development}

Christian Bökel and Michael Brand

Cold Spring Harb Perspect Biol 2014; doi: 10.1101/cshperspect.a017020

Subject Collection Endocytosis

Endocytosis: Past, Present, and Future Sandra L. Schmid, Alexander Sorkin and Marino Zerial

Rab Proteins and the Compartmentalization of the Endosomal System Angela Wandinger-Ness and Marino Zerial

Cargo Sorting in the Endocytic Pathway: A Key Regulator of Cell Polarity and Tissue Dynamics Suzanne Eaton and Fernando Martin-Belmonte

Unconventional Functions for Clathrin, ESCRTs, and Other Endocytic Regulators in the Cytoskeleton, Cell Cycle, Nucleus, and Beyond: Links to Human Disease

Frances M. Brodsky, R. Thomas Sosa, Joel A. Ybe, et al.

Endocytosis of Viruses and Bacteria Pascale Cossart and Ari Helenius

Lysosomal Adaptation: How the Lysosome Responds to External Cues Carmine Settembre and Andrea Ballabio

Reciprocal Regulation of Endocytosis and Metabolism

Costin N. Antonescu, Timothy E. McGraw and Amira Klip

Endocytosis and Autophagy: Exploitation or Cooperation?

Sharon A. Tooze, Adi Abada and Zvulun Elazar
Imaging and Modeling the Dynamics of

Clathrin-Mediated Endocytosis

Marcel Mettlen and Gaudenz Danuser

Endocytic Accessory Factors and Regulation of

Clathrin-Mediated Endocytosis

Christien J. Merrifield and Marko Kaksonen

The Complex Ultrastructure of the Endolysosomal

System Judith Klumperman and Graça Raposo

The Biogenesis of Lysosomes and

Lysosome-Related Organelles

J. Paul Luzio, Yvonne Hackmann, Nele M.G.

Dieckmann, et al.

Endocytosis, Signaling, and Beyond Pier Paolo Di Fiore and Mark von Zastrow

Clathrin-Independent Pathways of Endocytosis Satyajit Mayor, Robert G. Parton and Julie G. Donaldson

The Role of Endocytosis during Morphogenetic Signaling Marcos Gonzalez-Gaitan and Frank Jülicher

Role of Endosomes and Lysosomes in Human Disease

Frederick R. Maxfield

For additional articles in this collection, see http://cshperspectives.cshlp.org/cgi/collection/

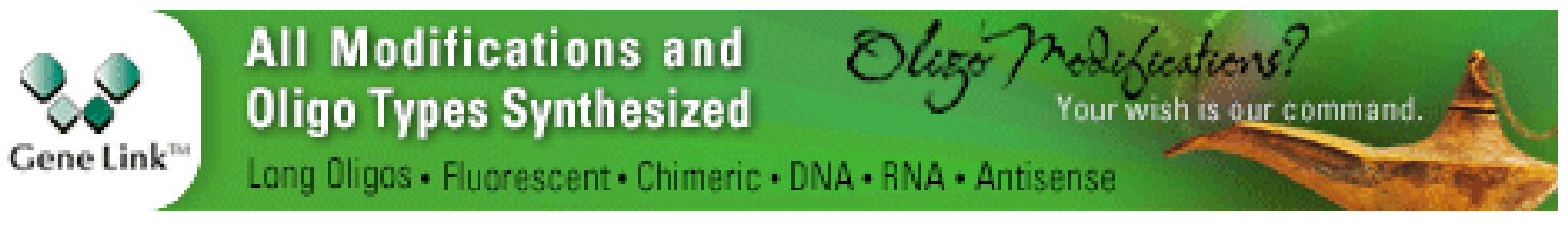


For additional articles in this collection, see http://cshperspectives.cshlp.org/cgi/collection/

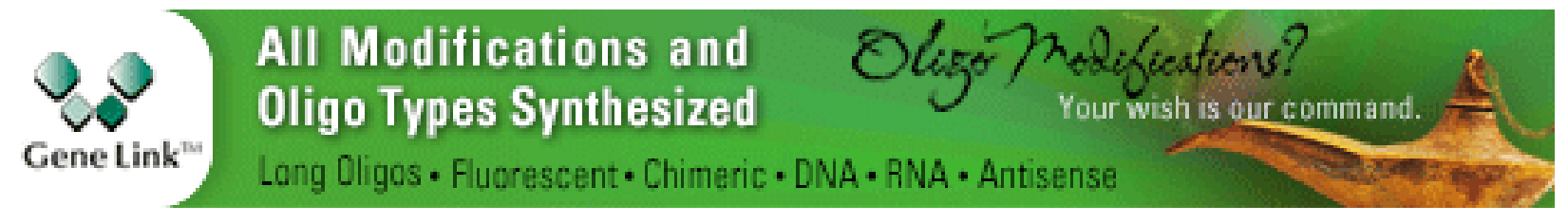

Copyright @ 2014 Cold Spring Harbor Laboratory Press; all rights reserved 